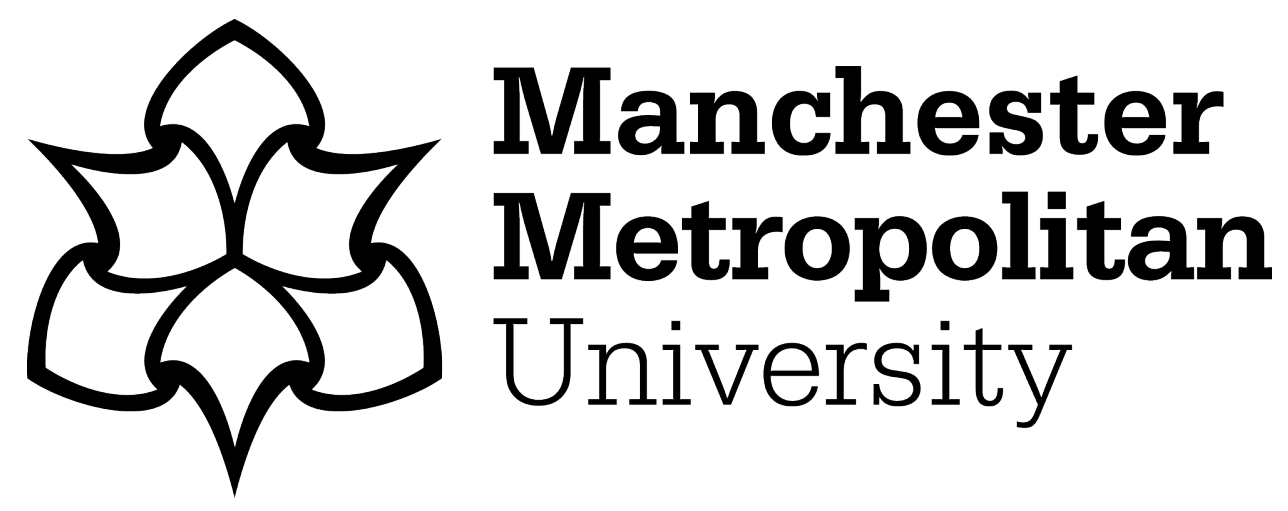

van Hooff, J ORCID logoORCID: https://orcid.org/0000-0001-8735-8758 (2017) An everyday affair: Deciphering the sociological significance of women's attitudes towards infidelity. The Sociological Review, 65 (4). pp. 850-864. ISSN 0038-0261

Downloaded from: https://e-space.mmu.ac.uk/617334/

Version: Accepted Version

Publisher: SAGE Publications

DOI: https://doi.org/10.1111/1467-954X.12417

Please cite the published version 


\title{
An everyday affair: Deciphering the sociological significance of women's attitudes towards infidelity
}

\author{
Jenny van Hooff
}

2016

\author{
The Sociological Review
}

doi:10.1111/1467-954X.12417

\begin{abstract}
This article draws on interview material to examine the recent hardening of attitudes towards infidelity. The visibility and apparent frequency of both consensual non-monogamy, as well as more common covert experiences, would suggest a challenge to dominant mononormative assumptions about the feasibility of lifelong monogamy. However, infidelity remains the lone area of adult sexual practice that is disapproved of under any circumstances (National Survey of Sexual Attitudes and Lifestyles, 2013). I argue that increasing hostility towards affairs is located in the discursive context of the 'specialness' of sex and the centrality of trust and communication to constructions of contemporary relationships. With the monogamous sexual couple at the centre of personal life, infidelity is regarded as a particular threat, revealing wider limitations to claims about the extent to which relationships have been detraditionalized.
\end{abstract}

\section{Introduction}

The recent academic focus and public fascination with consensual non-monogamous and polyamorous relationships (Barker and Langdridge, 2010) would suggest that dominant assumptions about the naturalness of monogamy are being contested. Yet polyamorous and open relationships remain in the minority, with the majority of men and women opting to keep their experiences of non-monogamy hidden in the form of covert encounters or 'affairs' (Jamieson, 2004). This article draws upon qualitative interview data with 20 heterosexual women in long-term relationships to examine why infidelity is apparently viewed with increasing intolerance in relationships, particularly when its frequency suggests that alternative approaches to lifelong monogamy should realistically be considered. Contextually, with infidelity understood as a common human experience, rather than as anything unusual or irregular, it is explicitly located as part of the ordinary and mundane and 
necessarily as a focus for the sociology of everyday life (Neal and Murji, 2015). It is important that in researching sexualities we should 'give higher priority to what goes on within less glamorous, more routine and normative sexual lives’ (Jackson, 2008: 35), as well as exploring diverse and subversive sexual practices.

Despite the apparent impact that infidelity has on individuals and relationships and the frequency with which it occurs, there has been a relative absence of critical sociological research (see Lawson, 1988; Duncombe et al., 2004 for notable exceptions), yet from a sociological perspective we can study how it breaches the social order in the most profound way (Lawson, 1988: 32). Infidelity occupies an unusual social space, as while hidden it is also ubiquitous. For example, there were a reported 37 million users (Hern, 2015) of the recently hacked 'married dating' website Ashley Madison (tagline: 'Life is short, have an affair'), and rates of infidelity in the UK are estimated at between 25 and 70 per cent of women and 40 to 80 per cent of men, dependent on the source (Figes, 2013). Nonetheless, social and sexual attitude surveys confirm that infidelity is the one area of adult sexual behaviour that is disapproved of under any circumstances (for example, National Survey of Sexual Attitudes and Lifestyles (NATSAL), 2013). For the purposes of this paper I draw on the most commonly used, although by no means definitive, understandings of infidelity: extra-dyadic sexual activities; sexual intercourse; and emotional betrayal (Moller and Vossler, 2014: 3). Duncombe and Marsden note the broad spectrum over which sexual infidelity spans, from brief one night stands, to long-term affairs which 'become imbued with the complex symbolism of uncontrollable desire, betrayal, risk, danger and secrecy' (2004: 141).

While the academic attention given to polyamory and consensual non-monogamy has been crucial in challenging compulsory heterosexuality (Barker, 2005; Klesse, 2006) and accompanying normative practices, it has eclipsed the already limited focus on more commonly experienced infidelities. Secret affairs are distinct from polyamorous relationships on multiple levels, most notably in that they are not openly negotiated, and are often intended to support traditional couple relationships rather than destabilize them. The general veneration of the sexual couple as the centre of intimate life, and the hostility which those caught 'cheating' usually face, perhaps reveals more about the extent of social change in personal life than the subversive sexual practices of a minority (Jackson, 2008), or permissive views towards young people's sexual behaviour (Langhamer, 2006). It has also been argued that the recent hardening in attitudes towards infidelity may be reflective of increasing contingency in relationships (Carter, 2012), with more women claiming that they would be willing to end a relationship on discovery of a partner's infidelity than in previous decades (Wouters, 2004), as well as a revival of romanticism (Kontula and Haavio-Mannila, 2004).

Using empirical data from two qualitative research projects, this paper explores heterosexual women's attitudes towards infidelity in long-term relationships. Generally participants were hostile to non-monogamy, whether consensual or not, with monogamy established as an assumed sexual practice and basic marker of commitment. With the traditional couple at the centre of personal life, infidelity is regarded as particularly threatening as it is perceived to withdraw intimacy and undermine mutual disclosure, often seen as the foundation of late modern relationships (Giddens, 1992). The motivation for individuals to engage in affairs, despite the potentially catastrophic personal and social consequences of exposure, including two reported suicides in the aftermath of the Ashley Madison hack (Thielman, 2015), is also examined here, through the experiences of three participants who are non-monogamous in 
their current relationships. It is argued that infidelity can be used as a lens to explore attitudes towards relationships more generally.

\section{A sociology of infidelity?}

The public fascination with infidelity has been driven by media attention given to high profile celebrity 'cheaters', highly rated television series including Scandal and The Affair, and recent cinematic adaptations of Anna Karenina and Madame Bovary. However, this has not been matched by academic attention within sociology, which has tended to focus on more publicly visible relationships rather than what is regarded as the highly private, individualized matter of infidelity. As such, the study of infidelity has been largely dominated by psychology (Morgan, 2004). Morgan notes the inevitable difficulties in defining what constitutes an affair, yet he argues that as sociologists we should be concerned with the ways in which affairs are actively and socially constructed as well as the range of meanings that are assigned to them (2004: 24). For example, traditionally infidelity is conducted in secret, which as well as being a major cause of anxiety, may also be part of the thrill of the relationship according to the participants of Lawson's (1988) classic study of adultery. Simmel discussed the sociological significance of secret affairs, which he argued are particularly threatening in modern societies which were shifting towards relationships based on the total personality (Craib, 1997: 150). The closer we are to someone, the more likely we are to be hurt by their lying or secrecy, yet deceit is often nececessary in order to maintain these relationships. Thus, the specificity of the affair as a distinct social relationship forms a key sociological concern.

Studies of infidelity are usefully located within the context of research on couple relationships more generally; affairs do not exist in isolation from more institutionally privileged relationships, although they do not always sit comfortably within the boundaries of 'personal life' and can be seen as an example of intimacy out of place. Sociological debate over the extent to which intimate relationships have been transformed in late modernity has focused in particular on the couple as the centre of intimate life. Detraditionalization theorists such as Giddens $(1991,1992)$ and Beck and Beck-Gernsheim $(1995,2002)$ have suggested the possibility of increasing fluidity and freedom in contemporary relationships, which are inherently fragile. For Giddens, a potential result is the predominance of the contingent, temporal, 'pure' relationship, within which 'trust can only be mobilised by a process of mutual disclosure' (Giddens, 1991: 6), and monogamy is negotiated, rather than taken for granted. Claims about the extent to which relationships have been detraditionalized have been contested (for example Jamieson, 1998; Jackson and Scott, 2004b; Gross, 2005). Within an increasingly depersonalized society, couple relationships play a key role in identity maintenance (Jamieson, 2004: 39), even to the openly non-monogamous participants of Jamieson's study. Research suggests that relationships are not as temporal or negotiated in everyday life as detraditionalization theorists have argued (Gabb et al., 2013), with most of us expecting our relationships to persevere despite the 42 per cent divorce rate (Office for National Statistics, 2014). Nonetheless, individuals may struggle with the 'inevitable loss of passion' (Perel, 2007: 4) that accompanies long-term coupledom, while being invested in monogamy as an ideal. For example, Anderson's research into male infidelity led him to conclude that the longer his participants were partnered, the more they desired recreational sex with others ( 78 per cent of his sample of 120 young men confessed to sexual infidelity), thus highlighting "the myth that monogamous desire is a natural product of "true love" (Anderson, 2010: 859). 
Gender differences in affairs are often highlighted, and although more married women are reportedly having affairs (Morgan, 2004), according to Reibstein and Richards (1992) we should be cautious of concluding that women's behaviour in this regard is becoming masculinized. Their research into marriage and affairs in Britain and the US concluded that women tend to become more emotionally involved than men, although any differences were subtle and complex (Reibstein and Richards, 1992: 110). Women also tend to locate affairs more in the context of their primary relationships, explaining that they were unhappy with their partners (in Allan's 2004 research), in contrast to male respondents who viewed affairs independently from their other relationships. If female infidelity is less visible it may be because the consequences for women caught 'cheating' are higher; globally it is the leading cause of domestic violence and divorce (VanderVoort and Duck, 2004), and generally the sexual double standard remains embedded in Western societies (Rahman and Jackson, 2010), meaning that women are judged more harshly for the same sexual behaviour as men, with female 'adulterers' tending to pay a higher 'emotional, material and social price for their transgression than men' (Langhamer, 2006: 110).

From this perspective, 'affairs can be seen as a lens through which to study the complex workings of the gender order and sexual politics in late modern society' (Morgan, 2004: 26). A critique of monogamy is a well-established tenet of feminist thought, focused on the idea that its main beneficiaries are men at the expense of women (Ritchie and Barker, 2007). Jackson and Scott (2004a) highlight the importance of non-monogamy as part of a wider resistance of individualistic coupledom and marriage, however, where feminist writers have advocated for female non-monogamy, openness is key in resisting heteronormative relationship conventions. Perceptions of infidelity are heavily gendered; as Annette Lawson notes, 'adultery is about more than marriage. It is about relations between women and men. Indeed it is about the nature of the whole society' (1988: 32). The broader aim here is to examine the reasons for our increasing intolerance towards a behaviour that is frequently revealed to be a common human experience, and contextually what this reveals about intimate relationships more generally.

\section{Researching infidelity}

This paper is based on qualitative research that investigates women's experiences and expectations of their primary relationships. I draw on a larger project, that explored the extent to which heterosexual couple relationships have become increasingly contingent and detraditionalized (van Hooff, 2013) alongside a more recent project specifically exploring the sexual and intimate lives of a small number of women in long-term heterosexual relationships (van Hooff, 2015). The importance of sexual fidelity emerged in all of the interviews with the 12 women aged 20-35 in long-term heterosexual relationships from the earlier study, and are drawn on here. Sexual and intimate practices form the focus of the more recent research project, which takes the form of qualitative interviews with eight women aged between 26 and 38, with non-monogamy emerging as a theme. Three of the women in the later study described being unfaithful to their current partners (although other participants discussed infidelities in previous relationships). Each in-depth interview lasted between one to two hours, and was recorded, transcribed, coded and analysed using thematic analysis in order to identify common themes. The characteristics of both sets of participants are similar demographically, with all of the participants educated to at least degree level or equivalent and employed in professional occupations, which suggests that they possess the requisite economic and cultural capital to allow them to benefit from any late modern transformations in intimacy (Jackson and Scott, 2004b: 240). However, it should be noted that interviewing 
women in intact relationships builds a conservative bias (Lewis, 2001: 150) into research findings; the general hostility to infidelity could be interpreted partly as a result of the participants' relationship statuses.

Infidelity is a particularly sensitive research topic (I have intentionally avoided the term adultery, which legally refers to extra-marital infidelity), and the potential harm involved to research participants in terms of disclosure should not be underestimated. Participants' names and identifying characteristics were changed, and tape-recorded interviews were deleted upon transcription. Nonetheless, recruiting participants for both projects proved challenging, although the focus was not specifically infidelity. That only three participants confessed to infidelity in their current relationships speaks to its transgressive nature, although they appeared happy and possibly relieved to share their experiences. Participants were sampled using convenience and snowball sampling methods, which were useful in attracting participants with similar features, although made for a sample of limited diversity. All of the participants worked full-time, many in similar professional fields, including medicine, criminal justice and education, all lived in either north-west or south-east England, only two were parents, they were predominantly white British (two were of mixed heritage, one was British Asian), eight were married, seven were engaged to be married and five were cohabiting, and all were in co-resident relationships. The mean age of participants was 33 . Any claims or comments relating to factors such as ethnicity or social class are limited by the small sample size and lack of data collected about these categories, and the paper instead focuses on the qualitative experiences of and attitudes towards infidelity and monogamy.

Furthermore, as affairs are taken to be a most intimate and private matter (Morgan, 2004), disclosing information about it to an interviewer may have made some participants uncomfortable. I attempted to engage in 'de-tabooing' (Lawson, 1988: 352) by avoiding terms that carried any connotations of shame; however, I was also conscious of not wanting to 'deceive participants into saying more than they were comfortable with. In-depth interviews as a research method created an environment that was particularly useful for eliciting information about the participants' sexual lives (O'Connell Davidson and Layder, 1994), as in this context they 'allow the greatest probing of individual knowledge' (Eyre 1997: 9).

\section{Openness and commitment}

Claims about the democratization or queering of sexual relations (eg Giddens, 1992; Roseneil, 2000) are countered by evidence that in long-term same-sex (Heaphy and Smart, 2011) and heterosexual (van Hooff, 2013) relationships, monogamy is an assumed sexual practice. As such, it is not usually openly discussed by partners, indeed sexual exclusivity is understood implicitly and explicitly as a sign of commitment to a relationship (Carter, 2012). Sex before marriage is accepted and even encouraged, notwithstanding the entrenched sexual double standard, yet committed long-term relationships retain traditional rules about monogamy, despite NATSAL (National Survey of Sexual Attitudes and Lifestyles, 2013) figures showing that 25 per cent of men and women who are in a relationship 'do not share the same levels of interest in sex' as their partner.

Carter (2012) explores issues of commitment in her research, and finds that for young women it is almost always accompanied by traditional expectations of sexual fidelity. Moreover, evidence suggests that we are increasingly less tolerant of infidelity, with the percentage of young women who considered an act of sexual infidelity enough to end a relationship rising 
from 41 per cent in 1979 to 63 per cent in 1989/93 (Wouters, 2004: 138). This is paralleled by recent NATSAL (ibid) data, with the percentage of female respondents considering adultery 'always wrong' increasing from 53 per cent in 1990 to 70 per cent in 2012, running against the trend of increasingly tolerant attitudes with regards to other areas of sexual activity. For the participants interviewed here, monogamy is inextricably tied to commitment, love and trust:

I'd be heartbroken if Ian cheated on me, I mean I don't know if I'd leave him, it would depend on whether we had kids, you know. (Jane)

It's happened to me in a previous relationship. No ... How could you stay with someone who was that much of a shit they'd cheat. For me you couldn't trust them ever again. (Chloe)

You just don't do that to someone you're supposed to be in love with, you know, how would you get past it in a relationship I don't know. People do I suppose but I don't know how. (Sara)

The monogamous couple relationship is perceived to be the only legitimate sexual outlet for participants, with transgressions regarded as cause to potentially end the relationship, and detailed in language such as 'cheating'. The words and phrases used to describe nonmonogamous relationships are almost universally negative, depicting the participants as immature, untrustworthy or sociopathic. As Kipnis writes, adultery has become a 'transparent sign for tawdriness and bad behavior' (1998: 294). Rates of infidelity in heterosexual marriage are often stated as over 60 per cent (Robinson, 1997), yet anything other than lifelong monogamy is not openly tolerated. Covert affairs are usually condemned because they contain not only secrecy, but also active deceit (Jamieson, 2004), and participants were clear that the greater betrayal lay in being deceived or deceiving one's partner rather than the act of sexual infidelity itself:

The thing that I couldn't forgive is that it's playing by different rules, it's not fair. (Kate)

I think I'd want to forgive, but it would be the lying rather than the sex, by the person that you're supposed to trust most, who's supposed to have your back. Not sure how people do. (Hannah)

The theme of dishonesty also emerges in the accounts of Kim and Amita, who discuss having been unfaithful in a previous (Kim) and ongoing relationship (Amita):

I did cheat on my previous partner. I found the guilt to be horrendous. I cheated instead of breaking up, it was wrong because it was dishonest. (Kim)

The first time we did it I was stunned ... I felt terrible, literally I couldn't get out of bed or speak for a week, I couldn't tell anyone, I was devastated that I was the kind of person that could do this, you know to cheat on, lie to, someone you're supposed to love you really are the shittiest person. (Amita)

The data here suggests that the participants' issues with infidelity lay with the dishonesty involved, suggesting a shift away from morality based on sexual practice. Communication 
and honesty are increasingly valued in our intimate relationships, and the existence of secret affairs undermine these qualities. Morgan (2004) draws on Simmel's work on secrets to examine infidelity and deceit, which he argues, "points to the possibilities of a second world existing alongside, beneath, or behind the manifest world' (2004: 20). He suggests that the idea that our partners (or friends, colleagues, parents) may be engaging in a secret life is profoundly disturbing, and yet the rate at which infidelity occurs gives us an indication of the complexity of everyday life. Trust is an oft-repeated basis of late modern relationships, however, as Perel (2007) points out from a therapeutic perspective, one of the contradictions of Giddens's (1992) pure relationship is that it relies on intimate knowledge of all of our partners' thoughts and actions, rather than trusting that secrets are important to relationships in order for individuals to maintain a distinct sense of identity. Smart writes of the 'modern cultural distaste for secrets' (2007: 127), which contributes towards an increasing intolerance for affairs. She refutes the presumption that openness will create an equality of knowledge amongst individuals who will then become equally positioned in relation to each other (Smart, 2007: 127). As evidenced by the Ashley Madison hack, the secrets formed today may be more vulnerable to disclosure than those forged by previous generations (Smart, 2007: 122).

While this 'will to truth' (Foucault, 1979) would appear to be a contributing factor in the hardening of attitudes towards infidelity, participants were almost equally hostile to openly non-monogamous relationships. Furthermore, deceit in other areas of a relationship, however serious, were not viewed in the same relationship-ending light as sexual infidelity. For example, Zoe described discovering that her partner, who she was due to marry, was heavily in debt to credit card and payday loans companies after a receiving a traumatic visit from a bailiff:

I was so upset, I had no idea, he never told me anything. I had to deal with that as I was planning the wedding. God. In the end my dad lent him the money and he's still paying it off, it'll take years. And it's my credit rating that's fucked too, just because he needs to have the newest iPhone and everything bought from Selfridges, whatever.

\section{Did you think about calling the wedding off, leaving?}

No, never. In the end, it's not like he cheated or anything.

While Zoe's partner repeatedly lied to her about his debt, in the process damaging her financial status, his actions are viewed as less transgressive than infidelity, which suggests that there is something specific about the sexual nature of the act which draws disapproval. Jackson and Scott offer a challenge to the 'special' status accorded to sex in this context; 'Why is having sex with someone other than a given partner equated with betrayal? Why do we call it infidelity? There are far worse forms of betrayal and faithlessness' (Jackson and Scott, 2004a: 155).

Using Morgan's (2011) framework of 'family practices' to examine friendship and intimate practices, Cronin (2015: 2) argues that the couple is the pivot around which most people organize their lives and value other relationships, with intimacy framed as a finite resource to be distributed using a principle of scarcity. From this perspective, affairs are particularly threatening as they withdraw intimacy from the couple, without the knowledge of the other partner in the primary relationship. As Jamieson points out, 'couple arrangements remain a cherished ideal' (2004: 36); in fact we can see from other research (Gabb et al., 2013; van 
Hooff, 2013) the increasing centrality of the sexual couple to personal life. Where previously various roles in our lives were filled by a host of actors, our partners today face the unenviable task of having to both meet our needs for predictability, stability and support as well as adventure, novelty and seduction (Perel, 2007).

\section{Doing non-monogamy and infidelity}

The majority of the participants drew on moral frameworks depicting non-monogamy as morally dubious, whether consensual or not. Jane's comment; 'If you need to have sex with other people, then your relationship's in trouble', illustrated a theme that emerged strongly from the data; that non-monogamy was symptomatic of underlying issues within a relationship, regardless of whether it was openly negotiated or covert. Similar findings emerged in Carter's research, as for her female participants monogamy and fidelity constitute a basic level of commitment without which a relationship is considered 'not worth having' (2012: 145). For the participants interviewed here it was also generally assumed that if a relationship was 'open' this was because one partner had coerced the other:

I'd consider an open relationship, but I'd have to be socialised into it because it defies some of my expectations and ideas about what a relationship is and I'd have to get over the jealousy side of things. I wouldn't say never, but I would say I'd prefer not to go down that road. (Kim)

If he asked me for an open relationship I'd have some major questions about what he'd been up to. And then I'd tell him to piss off. (Chloe)

It's me that needs to do this it wouldn't be fair to pressure him into an open relationship, I should just deal with it privately. Besides I don't think it'd go down too well to be honest. (Lena)

Open relationships were not an option for most participants, with the idea of sex or other intimate or emotional contact with an 'outsider' deeply threatening to their sense of what it meant to be part of a couple. The idea of discussing non-monogamy was often enough to raise suspicions or doubts about commitment and fidelity, which pushed participants into secret affairs, as in Lena's case. Consensual non-monogamy was generally considered to be a dangerous option by participants, with the guilt and jealousy involved perceived to threaten and destabilize a relationship:

If he has a much higher sex drive than you would you not consider an open relationship?

You mean sleep with other people? You're kidding? God no. Like I'm going to say to him 'Darling, you know that twenty-five year old you fancy at work - go for it'. I don't see how that works. (Sara)

\section{Would you consider a non-monogamous relationship with Steve?}

Er. Well. There's no way I could cope with him being with anyone else, it would be torture. I just don't know how you would deal with that, for me if I was guaranteed 
that he would never ever find out and that I wouldn't feel any guilt then I'd do it, of course. But I think that the guilt would kill me. (Hannah)

Monogamy is viewed very much as the 'natural mode of human relating' (Barker and Langdridge, 2010: 750) in participants' discussions, with alternatives seen as threatening and potentially disastrous to relationships. However, three of the women interviewed in the later research project confessed to infidelity in their current relationships. The first was Amita, who qualified her infidelity (an ongoing sexual relationship with one of her husband's friends) as a response to her husband's sexual rejection of her; nevertheless this is something that had caused her great emotional distress and contributed to the eventual breakdown of her marriage (which she reported back two months after the interview):

Well I suppose we're having an affair, though we don't really talk about it like that, but then I think if my husband doesn't want me am I expected not to have sex, does that seem fair? But I don't want to live like this; I want to be with one person, I know it's not right.

Infidelity is portrayed as morally wrong here by a participant who is actually engaging in it, which perhaps sheds some light on the common mismatch between attitudes and practice in sexual attitudes surveys. Rather than negotiate an openly non-monogamous relationship with her sexually uninterested husband, the pervasive cultural message that all of our emotional and sexual needs should be met in our primary couple relationships undermines any opportunity for Amita to take a less conventional approach. Yet Amita's depiction of the beginning of her affair highlights that while sex is often the basis for such relationships, their appeal runs much deeper; for her it was 'about being with someone again' and she describes 'being totally in love, though I've not told him that' with her lover. Amita's account illustrates the transformative nature of infidelity, as while affairs 'snatch moments of passion and sublime joy from months and years of vague unhappiness' (VanderVoort and Duck, 2004: 5) this is potentially threatening to established relationships.

Lena, the second non-monogamous participant, also described achieving a kind of validation through her (multiple) affairs that she felt she couldn't obtain in a traditional pair relationship. Although with her husband for almost a decade she had become habitually non-monogamous in the past three years following a short-term workplace affair:

[The first affair] went on for about six months, he ended it actually, he was married too and couldn't cope with the guilt, but what shocked me most was that there was no guilt, or hardly any, really. I think that's just what people tell you to stop you cheating because it was basically a massive thrill.

\section{Do you worry about getting caught?}

Definitely, but probably not as much as I should. I love my husband, we have a nice life together and I want to stay married, which I'm always really clear about, but that thrill that you get with someone new you just can't get it in a relationship. So, as well as a few one offs, I've had two other flings, I suppose you could call them and I get totally caught up in it all. I do worry though, if I got caught, or got an STI or something that really would be the end of my marriage. 
Lena states her preference for an openly non-monogamous relationship with her husband, but believes it wouldn't be tolerable for him and as a result keeps her extramarital relationships private, which involves a significant amount of emotional labour. From a feminist perspective Robinson (1997) has argued that non-monogamy in heterosexual relationships may be a way for women to exercise their agency and desire in defiance of dominant institutionalized heterosexuality, and Lena's account appears to support this, although the thrill of early romantic attachment appears to be as important as sexual satisfaction in her encounters. Long-term relationships are usually characterized by pragmatic considerations rather than romance (Carter, 2013), although research suggests that longer affairs often take on the monotony of the marital relationships that participants may have been attempting to escape (Duncombe and Marsden, 2004: 144). Lena demonstrates a keen awareness of this by timelimiting her affairs and moving on once they cease to provide the necessary escape. For the non-monogamous participants generally, infidelity is justified as a way of obtaining something that doesn't exist in their primary relationships.

Finally, Laura describes her extramarital relationship with a man she met in a bar locally and became as she describes 'obsessed with':

'We texted everyday, all the time, although we only met up a few times. It was so intense, I think I fell in love, just having someone look at you that way again. We did things, you know, there wasn't really opportunity for more.

\section{Did you think about leaving for him?}

In my head, constantly. But then I found out I was pregnant and I ended it, obviously. He doesn't know that was why. I hated being pregnant and I think it was because it forced me. But now I'm glad it didn't go any further, but I do still think about him sometimes, you know read his messages, you're not the same after something like that.

Again, the transformative (Duncombe and Marsden, 2004) nature of affairs is evoked in Laura's account. In researching infidelity, we should remember that individuals risk their relationships, families, property and reputations because 'affairs have a utopian edge in that they snatch moments of ecstasy from ordinary life' (VanderVoort and Duck, 2004: 12). While infidelity is part of the texture of everyday life, it occupies an unusual space, distinguished by secrecy and intensity. The relationships described by the non-monogamous participants are potentially destabilizing and threatening. However, the secrecy involved contributes to the heightened intensity that affairs often involve; openness would perhaps work to dissipate some of the threat to primary relationships, as proponents of polyamory have argued (Barker, 2005). While the sexual nature of infidelity is usually foreground as its defining feature, sex is seen as less of a threat to participants' relationships than the emotional intimacy of a longer-term affair. For the non-monogamous participants, the affair relationship is important in itself; Lena also describes having a number of casual encounters, however she dismisses them as barely relevant in the narrative of her infidelities. She is clear that the intimacy she enjoys with her affair partners is distinct from the love she has for her husband; however, it is a major part of the attraction for her.

As in Lawson's (1988) research, sex is usually the basis for non-monogamous relationships, although this is not to underestimate the deep sense of intimacy and commitment that participants often develop. It is this very intimacy, however, that is seen to destabilize and 
threaten participants' primary relationships. Kate's comment was typical: 'I think I could maybe forgive a drunken one night stand, but not one of those affairs you hear about that goes on for years, like a second marriage or something'. The data here has echoes of Duncombe and Marsdens' findings, with a female research participant stating, 'I don't mind if he fucks them, as long as he doesn't talk to them' (2004: 143 emphasis in original). Jackson and Scott (2004a) note the incongruity of women preferring to have long-term relationships with men who treat other women in this way rather than caring about the people they are intimate with. 'Meaningful' relationships do not invalidate other 'meaningful' relationships (Jackson and Scott, 2004a: 154), an assessment reinforced by other research findings which reveal that infidelity is not usually an evaluation of the principal relationship (Blow and Hartnett, 2005). According to this data, for those who are unfaithful, non-monogamy tends to be a reflection of opportunity, self-image, sexual satisfaction, and life course issues.

Participants were clear that men were more likely to be unfaithful, and consequently women were more harshly condemned when they failed to conform to the ideal of sexual fidelity:

I think men are more likely to cheat, yes, I look at my friends, things happen, you know, but with guys it's different. I have one good friend, and every woman he's been with he's cheated on, no matter how in love he is he just can't help himself. A woman wouldn't do that. (Sara)

It's happened to so many women I know, they've been cheated on. One friend of a friend, recently, she'd been living with her fiancé they've got a two year old, due to get married, and she finds out he's been shagging some, well, whatever, behind her back. (Rachel)

The reputational damage that accompanies infidelity often works to keep women from transgressing societal norms in this way, or at least means that they hide their affairs more successfully. Kim describes how she supressed the feelings she had for a colleague, whom she felt she shared a professional as well as a romantic 'connection' with, to avoid being unfaithful: 'I had a crush, and it was intense, there was texting, but I've noticed that they pass, so I try to sit it through as hard as it is.' In sexual matters, women are expected to display more self-control than men, who are viewed by both genders as less likely to resist the biological compulsion of their base urges (Anderson, 2012). Generally society is harder on women who have affairs, and the participants who disclosed their infidelities in the interviews demonstrated an awareness of this:

If I was caught it would be a disaster, everything ruined, marriage, friendships, family, work. I've seen it with friends, when men are it's almost a joke, or expected almost, but women, no. I can't even think about it. (Lena)

Morgan (2004) notes that while more married women are having affairs, they are also more successful at concealing them, which as well as providing evidence for the gendered division of emotional labour, suggests that women are more fearful of the consequences of being 'found out'. Participants were generally hostile to stories of infidelity and the motivations of individuals who engage in affairs, but they were particularly unsympathetic to women in this situation who are judged more severely than men. Those participants who have previously or currently been unfaithful are aware of these issues with their behaviour, and are often quick to condemn their own actions. They are also keen to emphasize the emotional intimacy involved in their affairs over the sexual aspects, perhaps because it is less acceptable for 
women to admit that sex is a motivating factor for infidelity. The 'connection' described by Kim, Amita and Laura is more of a justification in this context. These accounts suggest that stories of non-monogamy and infidelity remain heavily gendered, and while increasing numbers of women may be having affairs, as with other heterosexual relations, there is evidence here of continuity rather than drastic change.

\section{Conclusion}

This article has demonstrated the continuing centrality of the monogamous couple relationship as the ideal relationship form within the dominant heteronormative social narrative. Within this context infidelity is regarded as profoundly transgressive, and for the heterosexual women interviewed here, consensual non-monogamy is not seen as a negotiable alternative. The increasing disapproval of affairs is located in the context of the value placed on openness and communication, reflecting the ideals of Giddens's (1992) pure relationship, as well as the importance of love, sex and fidelity to modern marriage (Langhamer, 2006). The pervasive cultural message that all of our emotional and sexual needs should be met in our pair relationships undermines any opportunity for participants to consider or negotiate polyamorous or open relationships. And yet the cultural visibility of such arrangements foregrounds them as a viable alternative to the monogamous model, along with high rates of divorce which suggest that the traditional structural and societal constraints that kept couples in unsatisfactory relationships have dissolved. Yet, this and other research (Jamieson, 2004; Gabb et al., 2013; Cronin, 2015) locates the traditional sexual couple at the centre of our intimate life, with infidelity considered the ultimate threat, hence the hardening of attitudes towards it.

Undoubtedly a major part of the condemnation and disapproval of infidelity is the deceit involved, as trust and communication are prized elements of late modern intimate relationships (Giddens, 1992). However, as negotiated non-monogamy is rarely an option within long-term heterosexual partnerships, there is an inevitability about the continuation of this type of deception within relationships. Smart (2007) points out that the type of secrets we keep reflect the social conditions under which they are made. Rather than the liberalization of sexual practices, strict rules about the 'normal' expression of sexual desire and the role of the traditional couple in personal life are revealed in our attitudes towards non-monogamy, with infidelity's challenge to the couple establishing it as the most 'critical' of sexual practices (Kipnis, 1998: 295). Just as 'the couple' is part of the everyday (Gabb and Fink, 2015), so is 'the affair', although within a heteronormative framework the former is socially and institutionally privileged, and the latter remains marginalized and condemned. Polyamory and negotiated non-monogamy represent utopian ideals rather than realistic alternatives for the participants interviewed here, as heterosexual women are often entrenched in particular ideals and practices whereby conformity to particular relationship models constitute a marker of feminine success. Ultimately, while the ideal of monogamy fails to account for the reality of sexual infidelity, it will continue to be a source of relationship conflict and crisis. 


\section{References}

Allan, G. (2004) 'Being unfaithful: His and her affairs' In J. Duncombe, K. Harrison, G. Allan \& D. Marsden (eds.). The state of affairs: Explorations in infidelity and commitment. pp. 121-140. Mahwah, New Jersey: Lawrence Erlbaum Associates.

Anderson, E. (2010) “"At least with cheating there is an attempt at monogamy”': Cheating and monogamism among undergraduate heterosexual men', Journal of Social and Personal Relationships, 27, 851-872.

Barker, M. (2005) 'This is my partner, and this is my. . partner's partner: Constructing a polyamorous identity in a monogamous world', Journal of Constructivist Psychology, 18 (1), $75-88$.

Barker, M and Langdridge, D. (2010) 'Whatever happened to non-monogamies? Critical reflections on recent research and theory', Sexualities, 13 (6), 748-772.

Beck, U. and Beck-Gernsheim, E. (2002) Individualization. London: Sage.

Beck, U. and Beck-Gernsheim, E. (1995)The Normal Chaos of Love. Cambridge: Polity Press.

Blow, A.J., \& Hartnett, K. (2005). 'Infidelity in committed relationships II: A substantive review'. Journal of Marital and Family Therapy, 31, 217-233

Carter J. (2012) What is commitment? Women's accounts of intimate attachment.Families, Relationships and Societies 1 (2), 137-153

Carter, J. (2013) 'The curious absence of love stories in women's talk', The Sociological Review, 61 (4), 728-744.

Craib, I. (1997) Classical Social Theory, Oxford: Oxford University Press.

Cronin, A. M., (2015), 'Gendering friendship: couple culture, heteronormativity and the production of gender', Sociology.

Duncan S. (2011) 'Personal life, pragmatism and bricolage', Sociological Research Online, $16(4)$.

Duncombe, J. and Marsden, D. (2004) "'From here to epiphany...": Power and identity in the narrative of an affair'. In J. Duncombe, K. Harrison, G. Allan \& D. Marsden (eds.). The state 
of affairs: Explorations in infidelity and commitment. pp. 141-166. Mahwah, New Jersey: Lawrence Erlbaum Associates.

Figes, K. (2013) Our Cheating Hearts: Love And Loyalty, Lust And Lies, London: Virago. Foucault, M. (1979) The History of Sexuality, Volume 1, London: Allen Lane.

Gabb, J., Klett-Davies, M., Fink, J. and Thomae, M., (2013), Enduring Love? Couple Relationships in the 21st Century. Survey Findings Report, The Open University. http://www.open.ac.uk/researchprojects/enduringlove/files/enduringlove/file/ecmswebcontent/Final-Enduring-Love-Survey-Report.pdf.

Giddens, A. (1991) Modernity and Self-Identity: Self and Society in the Late Modern Age, Cambridge: Polity.

Giddens, A. (1992) The Transformation of Intimacy, Cambridge: Polity Press.

Gross, N. (2005) 'The Detraditionalization of Intimacy Reconsidered', Sociological Theory, $23(3), 286-311$.

Heaphy, B., Donovan, C. \& Weeks, J. (2004). ‘A different affair? Openness and nonmonogamy in same-sex relationships' In J. Duncombe, K. Harrison, G. Allan \& D.

Marsden (Eds.). The state of affairs: Explorations in infidelity and commitment.

pp.167-186. New Jersey: Lawrence Erlbaum Associates.

Heaphy, B, et al (2011) 'Just Like Marriage? A Study of Young Couple’s Civil Partnerships ESRC End of Award report', RES-062-23-1308. Swindon: ESRC

Hern, A (2015) 'Infidelity site Ashley Madison hacked as attackers demand total shutdown', The Guardian, 20th July, 2015, available at http://www.theguardian.com/technology/2015/jul/20/ashley-madison-hacked-cheating-sitetotal-shutdown.

Jackson, S. (2008) 'Ordinary Sex’, Sexualities, 11 (1/2), 33-37.

Jackson, S. \& Scott, S. (2004a). The personal is still political: Heterosexuality, feminism and monogamy, Feminism \& Psychology, 14 (1), 151-157. 
Jackson, S. and Scott, S. (2004b) 'Sexual Antinomies in Late Modernity', Sexualities, 7(2), $233-48$.

Jackson, S. and Scott, S. (2010) Theorizing Sexuality, Maidenhead: Open University Press. Jamieson, L. (2004) 'Intimacy, negotiated non-monogamy and the limits of the couple', In J. Duncombe, K. Harrison, G. Allan \& D. Marsden (eds.). The state of affairs:

Explorations in infidelity and commitment. pp. 35-58. Mahwah, New Jersey:

Lawrence Erlbaum Associates.

Jamieson, L. (1998) Intimacy: Personal relationships in modern societies, Cambridge: Polity.

Klesse, C. (2006) 'Polyamory and its "Others": Contesting the Terms of Non-Monogamy', Sexualities, 9(5), 565-583

Kipnis, L. (1998) ‘Adultery’, Critical Inquiry, 24(2), 289-327.

Kontula, O. and Haavio-Maanila (2004) 'Renaissance of romanticism in the era of increasing individualism' In J. Duncombe, K. Harrison, G. Allan \& D. Marsden (eds.). The state of affairs:

Explorations in infidelity and commitment. pp. 79-102. Mahwah, New Jersey:

Lawrence Erlbaum Associates.

Langhamer, C (2006) 'Adultery in Post-war England', History Workshop Journal, 62, 86115.

Lawson, A. (1989) Adultery: An Analysis of Love and Betrayal, Oxford: Blackwell.

Lewis, J. (2001) The End of Marriage? Individualism and Intimate Relations, Cheltenham: Edward Elgar Publishing Ltd.

McNay, L. (1999) 'Gender, Habitus and the Field: Pierre Bourdieu and the Limits of Reflexivity', Culture \& Society, 16, 95-117.

Moller, N.P. and Vossler, A. (2014) 'Defining infidelity in research and couple counseling: A qualitative study', Journal of Sex \& Marital Therapy, DOI: 10.1080/0092623X.2014.931314 
Montemurro, B. (2014) 'Getting Married, Breaking up and Making up for lost time:

Relationship Transitions as turning points for women's sexuality', Journal of Contemporary Ethnography, 43 (1), 64-93.

Morgan, D.H.J. (2004) 'The sociological significance of affairs' In J. Duncombe, K. Harrison, G. Allan \& D. Marsden (eds.). The state of affairs: Explorations in infidelity and commitment. pp. 15-34. Mahwah, New Jersey: Lawrence Erlbaum Associates.

National Survey of Sexual Attitudes and Lifestyles (2013) 'Sexual attitudes and lifestyles in Britain: Highlights from Natsal-3', Available at http://www.natsal.ac.uk/media/823663/natsal\%20infographic.pdf.

O’Connell Davidson, J. \& Layder, D. (1994) Methods, Sex and Madness, London: Routledge. Office for National Statistics (2014) Divorces in England and Wales, 2012, Available at http://www.ons.gov.uk/ons/dcp171778_351693.pdf.

Perel, E. (2007) Mating in Captivity: Sex, Lies, and Domestic Bliss, London: Hodder \& Stoughton.

Rahman, M. and Jackson, S. (2010) Gender and Sexuality: Sociological Approaches, Cambridge: Polity Press.

Reibstein, J. and Richards, M. (1992) Sexual Arrangements: Marriage and Affairs, Heinman: London.

Reynolds, J. and Wetherall, M. (2003) 'The Discursive Climate of Singleness: The Consequences for Women's Negotiation of a Single Identity', Feminism and Psychology, 13(4), 489-510.

Richardson, D. and Monro, S. (2012) Sexuality, Equality and Diversity, Basingstoke: Palgrave Macmillan.

Ritchie, A. and Barker, M. (2007) 'Hot bi babes and feminist families: Polyamorous women speak Out', Lesbian and Gay Psychology Review, 8(2), 141-151.

Robinson, V. (1997) 'My baby just cares for me: Feminism, heterosexuality and nonmonogamy', Journal of Gender Studies, 6 (2), 143-157. 
Roseneil, S. (2000) 'Queer Frameworks and Queer Tendencies: Towards an understanding of postmodern transformations of sexuality', Sociological Research Online, 5 (3).

Smart, C. (2007) Personal Life. Cambridge: Polity Press.

Thielman, S. (2015) 'Toronto police report two suicides associated with Ashley Madison hack' The Guardian, 24/08/15, available at http://www.theguardian.com/world/2015/aug/24/toronto-suicides-ashley-madison-hack. VanderVoort, L. and Duck, S. (2004) 'Sex, lies, and... transformation' In J. Duncombe, K. Harrison, G. Allan \& D. Marsden (eds.). The state of affairs: Explorations in infidelity and commitment. pp. 1-14. Mahwah, New Jersey: Lawrence Erlbaum Associates.

van Hooff, J. (2013) Modern Couples? Continuity and Change in Heterosexual Relationships,

Aldershot: Ashgate.

van Hooff, J (2015) 'Desires, Expectations and the Sexual Practices of Married and Cohabiting Heterosexual Women', Sociological Research Online, 20 (4) 4.

Wouters, C. (2004) Sex and Manners: Female emancipation in the West 1890-2000, London, Sage Publications. 